\title{
Comparison of National/Regional Diabetes Guidelines for the Management of Blood Glucose Control in non-Western Countries
}

Philip Home $\cdot$ Jihad Haddad $\cdot$ Zafar Ahmed Latif •

Pradana Soewondo $\cdot$ Youcef Benabbas $\cdot$ Leon Litwak

Serdar Guler $\cdot$ Jian-Wen Chen $\cdot$ Alexey Zilov

To view enhanced content go to www.diabetestherapy-open.com

Received: January 31, 2013 / Published online: May 4, 2013

(c) The Author(s) 2013. This article is published with open access at Springerlink.com

\section{ABSTRACT}

Introduction: Development of higher standards for diabetes care is a core element of coping with the global diabetes epidemic. Diabetes guidelines are part of the approach to raising standards. The epidemic is greatest in

P. Home $(\bowtie)$

Institute of Cellular Medicine, The Medical School, Newcastle University, Framlington Place,

Newcastle upon Tyne NE2 4HH, UK

e-mail: philip.home@ncl.ac.uk

J. Haddad

Division of Endocrinology, Department of Internal Medicine, Prince Hamazah Hospital, Hani Rifai 34, Amman, Jordan

\section{Z. A. Latif}

Bangladesh Institute of Research and Rehabilitation in Diabetes, Endocrine \& Metabolic Disorder (BIRDEM), 122, Kazi Nazrul Ave. Shahbag, Dhaka, Bangladesh

P. Soewondo

Faculty of Medicine University Indonesia, Jl

Salemba Raya no 6 Jakarta, Pusat 10430, Indonesia countries with recent rises in income from a low base. The objective of the current study was to investigate the availability and nature of locally produced diabetes guidelines in such countries. Methods: Searches were conducted using Medline, Google, and health ministry and diabetes association websites.

\section{Y. Benabbas}

Department of Medicine, University Hospital of Constantine, Cité Geric bat.9 Ain-Smara, 25140 Constantine, Algeria

\section{Litwak}

Diabetes and Metabolism Section, Hospital Italiano de Buenos Aires, Lafinur 3050 Piso 88 Dpto. 2, (1425), Buenos Aires, Argentina

\section{S. Guler}

Ankara Numune Training and Research Hospital, Sihhiye, Ankara 06100, Turkey

J.-W. Chen

Novo Nordisk, International Operations A/S, Thurgauerstrasse 36, 8050 Zurich, Switzerland
A. Zilov
Department of Endocrinology, First Moscow State Medical University, 1 Pogodinskaya Street, Office 622, Moscow 119435, Russia 
Results: Guidelines were identified in 33 of 75 countries outside North America, western Europe, and Australasia. In 25 of these 33 countries, management strategies for type 1 diabetes were included. National guidelines relied heavily on pre-existing national and international guidelines, with reference to American Diabetes Association standards of medical care and/or other consensus statements by $55 \%$, International Diabetes Federation by $36 \%$, European Association for the Study of Diabetes by $12 \%$, and American Association of Clinical Endocrinologists by $9 \%$. The identified guidelines were generally evidence-based, though there was some use of secondary evidence reviews, including other guidelines, rather than original literature reviews and evidence synthesis. In type 1 diabetes guidelines, the option of different insulin regimens (mostly meal-time + basal or premix regimens) was recommended depending on patient need. Type 2 diabetes guidelines either recommended a glycosylated hemoglobin target of $<7.0 \%(<53 \mathrm{mmol} / \mathrm{mol})(70 \%$ of guidelines) or $<6.5 \%(<47 \mathrm{mmol} / \mathrm{mol})(30 \%$ of guidelines) as the ideal glycemic target. Most guidelines recommended a target fasting plasma glucose that fell within the range of 3.8-7.2 mmol/L. Most guidelines also set a 2-h post-prandial glucose target value within the range of $4.0-8.3 \mathrm{mmol} / \mathrm{L}$.

Conclusion: While only a first step in achieving a high quality of disease management, national guidelines of quality and with fair consistency of recommendations are becoming prevalent globally. A further challenge is implementation of guidelines, by integration into local care processes.

Keywords: Diabetes; Fasting plasma glucose; Guidelines; Non-western countries; Local care;
Post-prandial glucose; Type 1 diabetes; Type 2 diabetes

\section{INTRODUCTION}

The worldwide prevalence of diabetes was estimated as 366 millions in 2011 (8.3\% of the population), and is predicted to rise to 552 millions (9.9\%) by 2030 [1]. The total number of excess deaths due to diabetes in 2011 in the 20-79 age group was estimated to be nearly 4.6 million (6.8\% of global deaths) [2]. According to forecasts, diabetes will have an increasing impact on years of life lost due to premature death and disability, shifting from the eleventh to seventh most common cause of death by 2030 [3]. In addition, diabetes has an important economic burden; globally, $12 \%$ of health expenditure was expected to be spent on diabetes in 2010 [4]. The greatest increases in diabetes prevalence have occurred in countries in economic transition, in particular in the Middle East, sub-Saharan Africa, China, and the Indian subcontinent [5]. This has the potential to put severe strain on healthcare systems in these countries [6-8].

There are a number of internationally recognized guidelines, algorithms, and position statements for the diagnosis, control, and management of diabetes [9-13], covering a range of different components of diabetes care, often with an emphasis on glucose-lowering therapies. These factors together with updates make use and implementation of the latest versions of the guidelines desirable but challenging [14-18]. However, implementation of guidelines for the management of diabetes has beneficial effects for the individual with diabetes, including a significant reduction in complications associated with diabetes, such as hospitalizations [19]. 
Despite the increasing burden of disease, measures of the use of guidelines repeatedly show poor implementation of, and adherence to, current recommendations [20, 21]. The quality of disease management is reduced because there is a gap between guideline recommendations and clinical practice [21]. Amongst reasons for non-implementation of guidelines may include poor access to the guidelines for clinicians, and the reduced access to healthcare resources of the target population [22].

Development and implementation of local standards of care quality to ensure 'local ownership' are considered important in securing a basis for guideline implementation [23]. Indeed, implementation of diabetes clinical practice guidelines have resulted in increases in the percentage of patients reaching glycosylated hemoglobin $\left(\mathrm{HbA}_{1 \mathrm{c}}\right)$ and low-density lipoprotein (LDL) targets [23, 24]. Compliance with national standards of care has been shown to make a substantial difference in the control of chronic diseases, such as diabetes $[21,25]$.

The purpose of the current study was to identify the establishment of national guidelines for the management of diabetes for a range of countries where income is changing from a low base, to investigate the coverage of these local guidelines, and to discuss the differences between different local guidelines and between local and international guidelines.

\section{METHODS}

\section{Search Strategy and Terms}

Searches were conducted using Medline, Google, and health ministry and diabetes association websites. Medline searches used the term 'diabetes' combined with 'guideline' or 'recommendations' or 'consensus', and the country names of non-western countries (outside North America, western Europe, and Australasia) available from International Diabetes Federation (IDF) member associations list. Countries included Albania, Algeria, Argentina, Azerbaijan, Bangladesh, Belarus, Bolivia, Brazil, Cameroon, Central African Republic, Chad, Chile, China, Colombia, Costa Rica, Cuba, Dominican Republic, Ecuador, Egypt, El Salvador, Estonia, Ethiopia, Gambia, Guatemala, Honduras, Hong Kong, India, Indonesia, Iran, Iraq, Israel, Ivory Coast, Jordan, Kazakhstan, Kenya, Kuwait, Lebanon, Libya, Lithuania, Malaysia, Maldives, Mauritius, Mexico, Morocco, Nepal, Nicaragua, Nigeria, Pakistan, Panama, Paraguay, Peru, Philippines, Puerto Rico, Qatar, Russia, Rwanda, Saudi Arabia, Senegal, Seychelles, Singapore, Slovakia, Slovenia, South Africa, South Korea, Syria, Taiwan, Tanzania, Thailand, Tunisia, Turkey, United Arab Emirates, Uganda, Ukraine, Uruguay, and Venezuela, or their regions (e.g., South America). Countries with guidelines were grouped into four regions: North Africa and Middle East, East and South Asia, Central and South America, and 'Other' (Table 1). Google searches were made using similar terms and combinations of terms to those listed above. Google searches were also run for ministry of health and diabetes association websites in the individual countries listed above, and those websites searched for guidelines.

\section{Inclusion Criteria and Translation}

Identified guidelines were retained for further analysis if they made recommendations for use or titration of glucose-control therapies in type 1 or type 2 diabetes; or if they contained 
Table 1 Breakdown of non-western countries with identifiable national guidelines by region

\begin{tabular}{llll}
\hline $\begin{array}{l}\text { North Africa and Middle East } \\
(\boldsymbol{n}=\mathbf{1 1})\end{array}$ & $\begin{array}{l}\text { East and South Asia } \\
(\boldsymbol{n}=\mathbf{9})\end{array}$ & $\begin{array}{l}\text { Central and South America } \\
(\boldsymbol{n}=\mathbf{5})\end{array}$ & $\begin{array}{l}\text { Other } \\
(\boldsymbol{n}=\mathbf{8})\end{array}$ \\
\hline Algeria & Bangladesh & Argentina & Belarus \\
Egypt & China & Brazil & Kazakhstan \\
Iraq & India & Chile & Israel \\
Jordan & Indonesia & Mexico & Kenya \\
Lebanon & Malaysia & Venezuela & Russia \\
Libya & Singapore & & Turkey \\
Morocco & South Korea & & Ukraine \\
Saudi Arabia & Taipei & & South Africa \\
Syria & Thailand & & \\
Tunisia & & & \\
United Arab Emirates & & & \\
\hline
\end{tabular}

guidelines specific for control of post-prandial glucose (PPG) levels or hypoglycemia; or special groups, such as children, the elderly, or those with complications. Guidelines were not included if they only dealt with lifestyle management, patient education, or psychological care; or were only concerned with screening and diagnosis; only concerned with non-glucose cardiovascular risk factors; or were specific to monitoring of glucose control, or specific to management of specific complications, including preventative foot care. If more than one guideline was available from any country, the authors relied on the knowledge of a local Novo Nordisk clinical advisor to advise on the main guideline in clinical use.

Guidelines that were not in English were translated using Google translate, including translations from Spanish, Portuguese, French, Indonesian, Hebrew, and Thai. Some guidelines could not be translated using the Google translate program and in these instances the guidelines were translated and tabulated by a local clinical advisor who was a native speaker, kindly provided by the local Novo Nordisk affiliate.

\section{Analysis}

The following parameters were assessed in the national guidelines: the source of the guidelines, e.g., whether from a national society or from the ministry of health; year of most recent guideline; year of previous guidelines; whether national guidelines were specifically based on international guidelines or consensus documents; whether specific recommendations for pediatric populations, the elderly, and gestational diabetes were present; post-prandial control; management of hypoglycemia; recommended first-, second-, and third-line insulin treatment for type 1 diabetes (if any); and recommended first-, second-, and third-line therapies for type 2 diabetes (if any).

This article does not contain any studies with human beings or other animals performed by any of the authors. 


\section{RESULTS}

National guidelines for the management of glucose control were not identified for 42 $(56 \%)$ of the 75 countries; one or more guidelines were available for 33 countries (Table 1). The year of the latest national guideline (2003-2010) was available for 31 (94\%) of the 33 countries. Twenty-one (68\%) of 31 countries in this group had developed or updated national guidelines since 2008. The identified guidelines were generally evidencebased, though there was some use of secondary evidence reviews, including other guidelines, rather than original literature reviews and evidence synthesis.

\section{Origin of National Guidelines}

National guidelines were developed or supported by national ministries of health in $36 \%$ of countries, national diabetes societies/ associations in $58 \%$ of countries, and both the ministry of health and national diabetic association in $6 \%$ of countries.

Specific mention was made to source other national or international guidelines in the recommendations from 26 of 33 (79\%) countries. The World Health Organization (WHO) definition of diabetes was mentioned by ten (30\%) countries, reference to the American Diabetes Association (ADA) standards of medical care and/or other consensus statements was made by 18 (55\%) countries, IDF guidelines by 12 (36\%) countries, European Association for the Study of Diabetes (EASD) consensus statement by four (12\%) countries, Association Latin America de Diabetes (ALAD) guidelines by 1 (3\%) country, and American Association of Clinical Endocrinologists (AACE) guidelines by three (9\%) countries.

\section{Type 1 Diabetes}

National guidelines for type 1 diabetes, or provision for type 1 diabetes in broader guidelines, were available for 25 of 33 (76\%) countries (Table 2). Sixteen of the 25 countries (64\%) that provided recommendations for firstline insulin therapy suggested the option of more than one type of regimen according to individual requirements. Meal-time + basal insulin regimens and premixed insulin were recommended in $60 \%$ of guidelines as first-line treatment options. Insulin analogs, such as the rapid-acting insulins (aspart, lispro), the longacting insulins (glargine, detemir), and premixed insulin analogs, were specifically mentioned as available options in 18 of 25 (72\%) national guidelines.

Nine of the $25(36 \%)$ country guidelines specified a second-line insulin regimen. Intensification with a meal-time + basal regimen was specified by four countries, use of insulin pump therapy was specified by two countries, and three countries suggested more than one option for intensification. Two countries mentioned a third-line management option of intensification of meal-time + basal insulin therapy.

\section{Targets for Glycemic Control}

Targets for glycemic control varied between guidelines. However, all guidelines either recommended an $\mathrm{HbA}_{1 \mathrm{c}}$ target of $<7.0 \%$ ( $<53 \mathrm{mmol} / \mathrm{mol}$ ) $(70 \%$ of guidelines) or $<6.5 \%$ $(<47 \mathrm{mmol} / \mathrm{mol})$ (30\% of guidelines) as the ideal glycemic target (Table 3). Most (89\%) guidelines recommended a target fasting plasma glucose (FPG) that fell within the range of $3.8-7.2 \mathrm{mmol} / \mathrm{L}$, and the remaining guidelines set a FPG target of $<8.0 \mathrm{mmol} / \mathrm{L}$. Most (68\%) guidelines also set a 2-h PPG target 
Table 2 Non-western countries with national guidelines for type 1 diabetes or provision for type 1 diabetes within broader diabetes guidelines, and those with guidelines for type 2 diabetes

\begin{tabular}{|c|c|c|c|c|}
\hline & $\begin{array}{l}\text { North Africa } \\
\text { and Middle East }\end{array}$ & East and South Asia & $\begin{array}{l}\text { Central and } \\
\text { South America }\end{array}$ & Other \\
\hline \multirow[t]{10}{*}{ Type 1 diabetes $(n)$} & 7 & 9 & 4 & 5 \\
\hline & Algeria & Bangladesh & Argentina & Kazakhstan \\
\hline & Egypt & China & Brazil & Kenya \\
\hline & Iraq & India & Chile & Russia \\
\hline & Lebanon & Indonesia & Venezuela & Turkey \\
\hline & Syria & Malaysia & & Ukraine \\
\hline & Tunisia & Singapore & & \\
\hline & United Arab Emirates & South Korea & & \\
\hline & & Taipei & & \\
\hline & & Thailand & & \\
\hline \multirow[t]{12}{*}{ Type 2 diabetes $(n)$} & 11 & 9 & 5 & 8 \\
\hline & Algeria & Bangladesh & Argentina & Belarus \\
\hline & Egypt & China & Brazil & Kazakhstan \\
\hline & Iraq & India & Chile & Israel \\
\hline & Jordan & Indonesia & Mexico & Kenya \\
\hline & Lebanon & Malaysia & Venezuela & Russia \\
\hline & Libya & Singapore & & Turkey \\
\hline & Morocco & South Korea & & Ukraine \\
\hline & Saudi Arabia & Taipei & & South Africa \\
\hline & Syria & Thailand & & \\
\hline & Tunisia & & & \\
\hline & United Arab Emirates & & & \\
\hline
\end{tabular}

value somewhere within the range of $4.0-8.3 \mathrm{mmol} / \mathrm{L}$ and the remaining guidelines set a PPG target of either $<8.8 \mathrm{mmol} / \mathrm{L}$ or $<10.0 \mathrm{mmol} / \mathrm{L}$.

\section{First-line Medication Therapy for Glucose- Lowering in Type 2 Diabetes}

Overall, 33 countries had national guideline recommendations for type 2 diabetes (Table 2 ).
Most countries (67\%) recommended lifestyle changes either before or in conjunction with beginning therapy with oral glucose-lowering drugs (OGLDs).

In only one country (Mexico) metformin was not formally endorsed as first-line therapy, but this guideline made provision for use of any oral agent. In South Korea, first-line options included metformin, a glucagon-like peptide-1 (GLP-1) receptor agonist, a dipeptidyl peptidase- 
Table 3 Type 2 diabetes glycemic control targets across regions

\begin{tabular}{|c|c|c|c|c|}
\hline \multirow[t]{2}{*}{ Region } & \multicolumn{4}{|l|}{ Glycemic target } \\
\hline & $\begin{array}{l}\mathrm{HbA1c}<6.5 \% \\
(<48 \mathrm{mmol} / \mathrm{mol})(\%)\end{array}$ & $\begin{array}{l}\text { HbA1c }<7.0 \% \\
(<53 \mathrm{mmol} / \mathrm{mol})(\%)\end{array}$ & $\begin{array}{l}\text { FPG } \\
(\mathbf{m m o l} / \mathrm{L})\end{array}$ & $\begin{array}{l}\text { PPG } \\
(\mathrm{mmol} / \mathrm{L})\end{array}$ \\
\hline North Africa and Middle East & 30 & 70 & 4.4 to $<7.8$ & 5.5 to $<10.0$ \\
\hline East and South Asia & 43 & 57 & 4.4 to 8.0 & 4.4 to $<10.0$ \\
\hline Central and South America & 20 & 80 & 3.8 to 7.2 & 7.7 to $<10.0$ \\
\hline Others & 0 & 100 & 3.9 to $<7.0$ & 4.0 to 8.0 \\
\hline
\end{tabular}

$H b A 1 c$ glycosylated hemoglobin, $F P G$ fasting plasma glucose, $P P G$ post-prandial glucose

4 (DPP-4) inhibitor, an alpha-glucosidase inhibitor, or a sulfonylurea. In Russia, first-line options included metformin, a GLP-1 receptor agonist, or a DPP-4 inhibitor, especially if metformin is poorly tolerated. In all other countries (94\%), metformin was recommended as the first-line treatment. However, in $48 \%$ of countries who recommended beginning OGLD therapy with metformin, provision was also made for metformin to be used in combination with either another oral agent therapy if $\mathrm{HbA}_{1 \mathrm{c}}$ was $>8.0 \%$ ( $>64 \mathrm{mmol} / \mathrm{mol})$, or with insulin if $\mathrm{HbA}_{1 \mathrm{c}}$ was $>9.0 \%$ (>75 mmol $\left./ \mathrm{mol}\right)$.

Specific recommendations for non-obese, weight-unspecified, or metformin-intolerant people were available in guidelines from 26 (79\%) countries. Alternatives included sulfonylureas $\quad(77 \%$ of countries), thiazolidinediones (35\%), glinides (19\%), alphaglucosidase inhibitors (27\%), GLP-1 receptor agonists (19\%), or DPP-4 inhibitors (35\%).

\section{Second- and Third-line Medications for Glucose-lowering in Type 2 Diabetes}

In most instances, second-line therapy was recommended when blood glucose control was not maintained at a target $\mathrm{HbA}_{1 \mathrm{c}}$ level of $<53 \mathrm{mmol} / \mathrm{mol}(<7.0 \%)$, but some guidelines suggested up-titration if above $47 \mathrm{mmol} / \mathrm{mol}$
$(6.5 \%)$ or $>42 \mathrm{mmol} / \mathrm{mol}(>6.0 \%)$. In many guidelines, an interval of 3-6 months was suggested after starting metformin or other medication before a further medication was added. Most recommendations were for a second oral agent rather than an injectable; usually (in $66 \%$ of guidelines) addition of a sulfonylurea to metformin. Some guidelines also suggested alternatives to sulfonylurea for use as a second drug in combination therapy, including thiazolidinediones, DPP-4 inhibitors, or alpha-glucosidase inhibitors. GLP-1 receptor agonists were suggested as a second-line combination option by only 2 of 32 (6\%) guidelines. In some countries (46\%) when $\mathrm{HbA}_{1 \mathrm{c}}$ was $>9.0 \% \quad(>75 \mathrm{mmol} / \mathrm{mol})$, starting with basal insulin plus one OGLD was recommended as an option.

Twelve of 32 (38\%) guidelines suggested that insulin therapy could be considered second-line in conjunction with metformin or another oral agent. The type of insulin was unspecified in $42 \%$ of guidelines, but in $42 \%$ basal insulin as a single insulin was an option, and in 25\% premixed insulin was an option.

Third-line therapy was specifically mentioned in 30 guidelines, with an additional oral agent suggested as an option in $40 \%$ of these. Insulin therapy was suggested as an option by 25 of 30 (83\%) guidelines. Of these 
guidelines, the type of insulin was not specified in $44 \%$ of guidelines (e.g., insulin initiated according to the patients' needs), beginning with basal insulin was recommended in $44 \%$, with premixed insulin in 32\%, long-acting in $12 \%$, and $20 \%$ of guidelines allowed initiation with more than one specified insulin regimen (e.g., initiate with long-acting or long-acting plus rapid-acting or premixed).

Guidelines from 22 of 33 (67\%) countries made specific provision for post-prandial blood glucose control within their diabetes guidelines. There was little regional variation in these recommendations, with eight of 11 North African and Middle Eastern countries, six of nine South and East Asian countries, three of five Central and South American countries, and five of eight other countries suggesting this measure should receive attention. Four of these countries suggested the use of alpha-glucosidase inhibitors to improve post-prandial blood glucose control (Lebanon, Libya, Mexico, Tunisia), while eight suggested rapid-acting (meal-time) insulin analogs (Saudi Arabia, Malaysia, Singapore, South Korea, Brazil, Mexico, Belarus, Kazakhstan).

\section{Hypoglycemia Treatment Guidelines}

Guidelines from 23 of 33 (70\%) countries included recommendations for the management of hypoglycemia. While this was mainly for the use of oral carbohydrate for symptomatic hypoglycemia, the use of intramuscular or subcutaneous glucagon was the most widely recommended intervention for severe hypoglycemia.

\section{Special Groups}

Information was available for special groups of people with diabetes in guidelines from 31 of the
33 countries. Of these, 23 countries (74\%) had recommendations for the management of gestational diabetes, 16 of 31 (52\%) for the elderly, and 21 of 31 (68\%) for pediatric patients.

\section{DISCUSSION}

The development of insulin analogs and GLP-1 receptor agonists, and the increase in the number of available OGLDs have increased the number of glucose-lowering therapy options for people with type 1 or type 2 diabetes [26-28], while management of other conditions (elevated lipids and blood pressure, or complications) has also evolved [26-28]. Some clinicians find authoritative guidelines useful in giving direction to the appropriate management pathways, while others use them to endorse and review their own practice in the diverse areas of diabetes care [12]. While national and international guidelines, algorithms, and position statements on the management of diabetes, and more specifically on glucose-lowering medication, published by ADA, IDF, EASD, and ALAD, together with some high-quality national guidelines, seek to address the clear medical need for guidance in the management of diabetes, these may not meet the needs of local populations at the national or provincial level in non-western countries.

Not surprisingly, the national guidelines identified in this review relied heavily on preexisting international guidelines. In most countries, the latest version of national guidelines was published before 2012 and consequently could not contain reference to the latest position statement from ADA/EASD [17]. This may be problematic as there was significant change between 2009 and 2013 in glucose-lowering treatment options. Also endorsed in the new statement from ADA/ 
EASD was the approach to individualization of medical decision-making [17]. Ideas on individualizing management, and an approach to variation in provision of care according to available resources, were espoused by the 2005 IDF type 2 diabetes guideline, but changes were needed for the 2012 revision in light of new therapy options [16]. Also, the ADA standards in medical care is updated annually to include the latest available information on managing diabetes [18] while national guidelines are updated less frequently and may not reflect all new therapy options as they become available.

As this study focussed on adults, the authors have not included international pediatric type 1 diabetes guidelines, such as those from the International Society for Pediatric and Adolescents Diabetes (ISPAD), in the present analysis [29]. However, most national guidelines for type 1 diabetes in adults emphasized the importance of meeting the needs of individual patients when beginning and modifying insulin therapy, with mealtime + basal insulin regimens most commonly cited as being likely to meet individual requirements, especially for post-prandial blood glucose control and for reducing the risk of hypoglycemia. Insulin analogs, such as the rapid-acting insulins (aspart, lispro), biphasic insulins based on these, and the long-acting insulins (glargine, detemir), were specifically mentioned as available options in 18 of 25 (72\%) national guidelines for type 1 diabetes.

In the management of hyperglycemia in type 2 diabetes, most national guidelines were in agreement with international guidelines in their recommendation of metformin as the treatment of choice for first-line therapy, especially in obese patients, though the option of combination with another OGLD or insulin was addressed in $48 \%$ of countries. Likewise, most national guidelines acknowledged sulfonylureas as a first-line treatment option in people who were not obese and for those who could not tolerate metformin. This was in general agreement with recommendations in IDF guidelines and ADA statements on the use of sulfonylureas if and when metformin is insufficient, is not tolerated, or in people who are not overweight [16-18].

Differences do, however, appear in both national and international recommendations as to the use of second-line therapies if glucosecontrol targets are not attained within 3-6 months or if subsequent deterioration of glucose control occurs. While the cost-effective sulfonylureas are most commonly recommended, some guidelines also made provision for the addition of other OGLDs drugs, including thiazolidinediones, DPP4 inhibitors, and alpha-glucosidase inhibitors. Many guidelines (12 of 33) also suggest the option of injectables, GLP-1 receptor agonists, and insulin as a second-line therapy options, as does the recent position statement from the ADA/ EASD group [17].

A problem with international guidelines is that they can give so many alternative treatment options that the less specialist practitioner may fail to make the optimum treatment recommendations for each type of patient. In addition, complex regimens may lead to payors agreeing to reimburse the cheapest available option(s). National guidelines that allow multiple treatment options but discuss the benefits and weaknesses of individual classes of glucose-lowering therapies may then be closer to assisting health-care professionals in meeting the medical needs of people with type 2 diabetes.

Another consideration is whether provision is made in national guidelines for specific clinical situations, post-prandial blood glucose control, and hypoglycemia. Guidelines from $67 \%$ of countries in the study made some provision for PPG control, with use of a rapid- 
acting insulin as part of a meal-time + basal insulin regimen the most common recommendation, and an alpha-glucosidase inhibitor was recommended in some guidelines. Guidelines from $70 \%$ of countries made provision for hypoglycemia.

A limitation of the current study is that it has not been comprehensive in the inclusion of all available national guidelines for all the countries, but has specifically focussed on treatment guidelines, which may have introduced bias into the final analysis. A further limitation was that some national guidelines may have been inadvertently missed because they were not freely available on the internet or were restricted to a non-English website. Some countries may also have one or more national guidelines that they refer to. Furthermore, the study had to rely on translation of guidelines from the original language into English for many countries, and this may have led to the inclusion of inaccuracy or inconsistencies in the analysis. For guidelines that could not be translated using Google translation, the accuracy of the data depended on the interpretation of a local clinical advisor provided by Novo Nordisk who translated the guidelines from the native language. Also, the study did not include guidelines for special groups, such as recommendations for the management of diabetes during Ramadan [30-32]. However, the authors note that guidelines on the management of diabetes during Ramadan stress the importance of individualizing treatment to meet the patient's needs [30-32].

\section{CONCLUSION}

In conclusion, national guidelines were identified for 33 out of 75 (44\%) lower income countries, of which $76 \%$ also had guidelines for type 1 diabetes. Two-thirds of countries with national guidelines for type 2 diabetes had made the latest version of their guidelines available after 2008, enabling the latest treatment options to be included. Given that, the consensus algorithms developed by ADA/ EASD have been criticized because they were based mostly on expert opinion rather than on an evidence-based process [26, 30]. Therefore, it is notable that many national guidelines seem now to have adopted a more evidence-based approach. Furthermore, with regular updating to reflect the rapid pace of change in the management of type 2 diabetes, this suggests that quality national guidelines may benefit a wider international population of people with diabetes.

However, establishment of national guidelines is only the first step in achieving a high quality of disease management and more efforts need to be made for clinicians and patients to adhere to the recommendations of national guidelines, since glycemic control is still poor in the countries where this study was conducted.

\section{ACKNOWLEDGMENTS}

Sponsorship and article publication charges for this study were funded by Novo Nordisk International Operations. Analysis of the data from the national guidelines was made by ESP Bioscience, Crowthorne, UK. Each individual parameter was tabulated prior to arithmetic calculation. Editorial assistance was provided by John Clarke, ESP Bioscience Ltd, Crowthorne, UK. ESP Bioscience was funded by Novo Nordisk International Operations. Dr. Home is the guarantor for this article, and takes responsibility for the integrity of the work as a whole. 
Conflict of interest. PH or institutions with which he is associated receives funding from most manufacturers of glucose-lowering medications for his research, advisory and educational activities. JH has acted as a speaker for Novo Nordisk, Novartis, MSD, Merck Serono, and AstraZeneca, and an advisory board member for Novo Nordisk and Merck Serono. ZAL is an advisory board member and has been a principal investigator for Novo Nordisk. PS is an advisory board member for Novo Nordisk, Sanofi-Aventis, and Novartis. YB has participated in advisory boards and as a consultant for Novo-Nordisk. LL is a speaker and member of the Latin American Board of Eli Lilly, and the Argentinian Boards of Novo Nordisk, Novartis, Sanofi, BMS, and AstraZeneca. He is also a principal investigator of clinical trials run by Eli Lilly, Novo Nordisk, and AstraZeneca. SG has participated in international clinical trials sponsored by Novo Nordisk. J-WC is an employee of Novo Nordisk A/S. AZ has participated as a speaker for Abbott, AstraZeneca/BMS, Bayer, Berlin-Hemi, Novartis, Novo Nordisk, and Sanofi and has also participated in clinical trials sponsored by Lilly, Novartis, Novo Nordisk, and Sanofi.

Ethical Standard. This article does not contain any studies with human beings or other animals performed by any of the authors.

Open Access. This article is distributed under the terms of the Creative Commons Attribution Noncommercial License which permits any noncommercial use, distribution, and reproduction in any medium, provided the original author(s) and the source are credited.

\section{REFERENCES}

1. Whiting DR, Guariguata L, Weil C, Shaw J. IDF diabetes atlas: global estimates of the prevalence of diabetes for 2011 and 2030. Diabetes Res Clin Pract. 2011;94:311-21.

2. International Diabetes Federation. The IDF Diabetes Atlas 5th Edition: A summary of the figures and key findings. Available at: http://www.idf.org/ diabetesatlas/downloads. Accessed 30 Aug 2012.

3. Mathers CD, Loncar D. Projections of global mortality and burden of disease from 2002 to 2030. PLoS Med. 2006;3:e442.

4. Zhang P, Zhang X, Brown J, et al. Global healthcare expenditure on diabetes for 2010 and 2030 . Diabetes Res Clin Pract. 2010;87:293-301.

5. Huizinga MM, Rothman RL. Addressing the diabetes pandemic: a comprehensive approach. Indian J Med Res. 2006;124:481-4.

6. Abegunde DO, Mathers CD, Adam T, Ortegon M, Strong K. The burden and costs of chronic diseases in low-income and middle-income countries. Lancet. 2007;370:1929-38.

7. Arredondo A, Zuniga A. Economic consequences of epidemiological changes in diabetes in middleincome countries: the Mexican case. Diabetes Care. 2004;27:104-9.

8. Unwin N, Alberti KG. Chronic non-communicable diseases. Ann Trop Med Parasitol. 2006;100:455-64.

9. International Diabetes Federation. Global Guideline for Type 2 Diabetes: recommendations for standard, comprehensive, and minimal care. Diabet Med. 2006;23:579-93.

10. World Health Organization. Definition and diagnosis of diabetes mellitus and intermediate hyperglycaemia. Available at: http://www.who.int/ diabetes/publications/Definition\%20and\%20diagn osis\%20of\%20diabetes_new.pdf. Accessed 10 Jun 2012.

11. Ryden L, Standl E, Bartnik M, et al. Task Force on Diabetes and Cardiovascular Diseases of the European Society of Cardiology (ESC); European Association for the Study of Diabetes (EASD). Guidelines on diabetes, pre-diabetes, and cardiovascular diseases: executive summary. The Task Force on Diabetes and Cardiovascular Diseases of the European Society of Cardiology (ESC) and of the European Association for the Study of Diabetes (EASD). Eur Heart J. 2007;28: 88-136.

12. Nathan DM, Buse JB, Davidson MB, et al. European Association for the Study of Diabetes. Medical management of hyperglycemia in type 2 diabetes: a consensus algorithm for the initiation and adjustment of therapy: a consensus statement of 
the American Diabetes Association and the European Association for the Study of Diabetes. Diabetes Care. 2009;32:193-203.

13. American Diabetes Association. Standards of medical care in diabetes-2010. Diabetes Care. 2010;33(Suppl 1):S11-61.

14. American Diabetes Association. Standards of medical care in diabetes-2011. Diabetes Care. 2011;34(Suppl 1):S11-61.

15. American Diabetes Association. Standards of medical care in diabetes-2012. Diabetes Care. 2012;35(Suppl 1):S11-63.

16. International Diabetes Federation Clinical Guidelines Task Force. Global guidelines for type 2 diabetes. Available at: http://www.idf.org/globalguideline-type-2-diabetes-2012. Accessed 5 Dec 2012 .

17. Inzucchi SE, Bergenstal RM, Buse JB, American Diabetes Association; European Association for the Study of Diabetes, et al. Management of hyperglycemia in type 2 diabetes: a patientcentered approach: position statement of the American Diabetes Association (ADA) and the European Association for the Study of Diabetes (EASD). Diabetes Care. 2012;35:1364-79.

18. American Diabetes Association. Standards of medical care in diabetes-2013. Diabetes Care. 2013;36(Suppl 1):S11-66.

19. Sloan FA, Bethel MA, Lee PP, Brown DS, Feinglos MN. Adherence to guidelines and its effects on hospitalizations with complications of type 2 diabetes. Rev Diabet Stud. 2004;1:29-38.

20. Bouldin MJ, Low AK, Blackston JW, et al. Quality of care in diabetes: understanding the guidelines. Am J Med Sci. 2002;324:196-206.

21. Jenssen TG, Tonstad S, Claudi T, Midthjell K, Cooper J. The gap between guidelines and practice in the treatment of type 2 diabetes A nationwide survey in Norway. Diabetes Res Clin Pract. 2008;80:314-20.
22. Puder JJ, Keller U. Quality of diabetes care: problem of patient or doctor adherence? Swiss Med Wkly. 2003;133:530-4.

23. Engelgau MM, Narayan KM, Saaddine JB, Vinicor F. Addressing the burden of diabetes in the 21st century: better care and primary prevention. J Am Soc Nephrol. 2003;14:S88-91.

24. McCraw WM, Kelley PW, Righero AM, Latimer R. Improving compliance with diabetes clinical practice guidelines in military medical treatment facilities. Nurs Res. 2010;59:S66-74.

25. van Bruggen R, Gorter KJ, Stolk RP, Verhoeven RP, Rutten GE. Implementation of locally adapted guidelines on type 2 diabetes. Fam Pract. 2008;25:430-7.

26. Triplitt CL. New technologies and therapies in the management of diabetes. Am J Manag Care. 2007;13(Suppl 2):S47-54.

27. VanDeKoppel S, Choe HM, Sweet BV. Managed care perspective on three new agents for type 2 diabetes. J Manag Care Pharm. 2008;14:363-80.

28. Wasikowa RB, Basiak A. Progress in the treatment of diabetes type 1 and 2. Pediatr Endocrinol Diabetes Metab. 2007;13:47-51.

29. International Society for Pediatrics and Adolescent Diabetes. Clinical Practice Consensus Guidelines. Available at: http://www.ispad.org/FileCenter. html?CategoryID=5. Accessed 17 Jan 2013.

30. Al-Arouj M, Assaad-Khalil S, Buse J, et al. Recommendations for management of diabetes during Ramadan: update 2010. Diabetes Care. 2010;33:1895-902.

31. Karamat MA, Syed A, Hanif W. Review of diabetes management and guidelines during Ramadan. J R Soc Med. 2010;103:139-47.

32. Pathan MF, Sahay RK, Zargar AH, et al. South Asian Consensus Guideline: use of insulin in diabetes during Ramadan. Indian $\mathrm{J}$ Endocrinol Metab. 2012;16:499-502. 